\title{
ELEMENTOS PARA EL DISEÑO DE UN SISTEMA DE JUSTICIA CONSTITUCIONAL EN LOS ESTADOS FEDERALES
}

\author{
Enrique Uribe Arzate*
}

\begin{abstract}
RESUMEN
La justicia constitucional es un tema de actualidad en todo el mundo y especialmente en Latinoamérica, donde la democracia y el respeto a los derechos humanos demandan mejores escenarios para su desarrollo y garantía. Desde luego, la praxis de la justicia constitucional va de la mano con la forma de organización político-jurídica del Estado. Por eso, los Estados organizados de acuerdo al modelo federal necesitan un diseño ad hoc de justicia constitucional, pues la coexistencia de dos órdenes competenciales requiere la participación de los Estados-miembros, además de instrumentos jurídicos adecuados para dicha tarea.
\end{abstract}

JUSTICIA CONSTITUCIONAL - DERECHOS HUMANOS - ESTADOS FEDERALES

\section{Guidelines for the design of judicial review in federal states}

\begin{abstract}
Judicial review is an issue of modern times throughout the world and especially in Latin America, where democracy and the respect for human rights require better scenarios for their development and guarantee. Of course, the praxis of judicial review goes hand in hand with the state legal form. That is why federal States need an ad-hoc design of judicial review as the coexistence of two jurisdictional orders requires the participation of member states, in addition to legal instruments appropriate to that task.
\end{abstract}

JUDICIAL REVIEW - HUMAN RIGHTS - FEDERAL STATES

* Abogado, Doctor en Derecho, Profesor investigador en el Centro de Investigación en Ciencias Jurídicas, Justicia Penal y Seguridad Pública de la Universidad Autónoma del Estado de México, Francisco I. Madero 29, Villa Cuauhtémoc, Municipio de Otzolotepec, Estado de México, Código Postal 52080, Correo electrónico: eua@uaemex.mx

Artículo Recibido el 23 de marzo de 2006 y aceptado para su publicación por el Comité Editorial el 30 de mayo de 2006. 


\section{LA VISIÓN ACTUAL}

$\mathrm{H}$ oy casi nadie discute que el Estado Constitucional es perínclita aspiración de las sociedades de nuestro tiempo. En este escenario, la justicia constitucional entraña una de las más valiosas herramientas para la transformación del Estado y la consecución de sus fines; a nuestro parecer, esta cuestión cobra mayor relieve en Latinoamérica, donde la justicia constitucional es vista como insustituible mecanismo de equilibrio entre los poderes, vía segura para la garantía de los derechos fundamentales y poderoso motor para el arribo a mejores estadios de convivencia social.

Desde esta perspectiva -por su alto grado de especialización- la justicia constitucional debe ser diseñada con lineamientos específicos para cada Estado. ${ }^{1}$ Sin embargo, como desde el punto de vista teórico es difícil establecer tantas categorías como países existen, hemos elegido el modelo federal para determinar qué elementos deben converger en el intento por delinear un sistema de justicia constitucional adecuado, viable y eficaz.

En algunos países diseñados a partir de este modelo y que cuentan con una Suprema Corte de Justicia, la tarea en comento es realizada por el mismo órgano que desempeña la justicia ordinaria. ${ }^{2}$ Aunque todavía la línea divisoria entre ambas expresiones de la justicia puede ser difusa, lo cierto es que la yuxtaposición de estas dos actividades en un solo órgano acarrea dificultades - perceptibles en el aspecto funcional pero sobre todo en la eficacia de dicha tarea-. Por ello, en este trabajo partimos de una consideración doble: ¿Cómo deben organizarse las relaciones entre las instancias federal y local para llevar a cabo la justicia constitucional?, ¿Qué instrumentos jurídicos son los más recomendables?

En este punto, no sobra recordar que la justicia constitucional sigue siendo un tema poco comprendido. Prueba de ello, es que gran parte de la doctrina sigue anclada en la idea de que el control de la constitucionalidad es suficiente para garantizar la vigencia del Estado de Derecho. Desde luego, la defensa de las garantías constitucionales y el mantenimiento de las competencias entre los diversos niveles de gobierno, constituyen las dos grandes expresiones que no pueden estar ausentes en cualquier análisis sobre el tópico aquí destacado; empero, un verdadero sistema de justicia constitucional necesita estar armado con otros elementos que prima facie podrían mirarse desconectados de la estructura general; por citar dos, la democracia y los derechos humanos que guardan una relación de obligada reciprocidad. ${ }^{3}$ En algunos casos el asunto es todavía más delicado, pues se sigue lastrando la añeja creencia de que ciertas instituciones tradicionales ${ }^{4}$ son suficientes para combatir las variadas manifestaciones de actos y leyes contrarios a la Constitución.

\footnotetext{
${ }^{1}$ Superada la dualidad entre sistema concentrado y difuso, América latina ofrece una cantidad muy rica de sistemas "híbridos” de justicia constitucional.

${ }^{2}$ Véanse los casos de Argentina, México y Nicaragua, por mencionar algunos.

${ }^{3}$ Cappelletti, M., "Necesidad y legitimidad de la justicia constitucional”, en Tribunales constitucionales europeos y derechos fundamentales, Favoreu, L., et al., Centro de Estudios Constitucionales, Madrid, 1984, p. 632.

${ }^{4}$ Es el caso de México, donde la sacralización indebida del juicio de amparo-probada institución para la defensa de los derechos del gobernado- todavía hace pensar a algunos tratadistas que no hacen falta otros mecanismos para verificar el control de la constitucionalidad y realizar la defensa de la Constitución.
} 
Este es el panorama actual que grosso modo podemos describir en la materia que nos ocupa. Cabe agregar que su impronta cobra relieve a partir del reconocimiento de que el Estado Constitucional Democrático es el único posible y defendible, ${ }^{5}$ lo cual resalta la importancia que en la actualidad tienen los temas inherentes al control del poder, concretamente al control del ejercicio de la potestad estatal por quienes tienen atribuciones y competencia conferidos por la ley.

A partir de la idea de que el control del $\operatorname{poder}^{6}$ debe ser una actividad cotidiana y fundamental del Estado, la justicia constitucional ha tenido que plantearse constantemente cuál es el mejor modelo o sistema ${ }^{7}$ para verificar esta obligación estatal. En este sentido, como sabemos, son básicamente dos los sistemas existentes sobre el particular: El sistema de control por órgano político y el sistema de control por órgano jurisdiccional.

De acuerdo con esto, podemos identificar en algunos países una rara mixtura que ha generado confusión sobre la naturaleza de los variados instrumentos que al menos en el papel sirven para realizar la justicia constitucional. De esta forma, existen procedimientos que deben desahogarse a través de los órganos jurisdiccionales y otros que todavía están a cargo de los órganos de naturaleza política. La valoración que podemos hacer sobre estos últimos se expresa en la afirmación de su ineficacia generalizada y la pertinencia de su modificación. Esta afirmación explicada en otros trabajos, ${ }^{8}$ nos permite pasar de inmediato al análisis de la justicia constitucional en una doble vertiente: En su contexto actual y en la perspectiva deonto-teleológica.

\section{ESCENARIOS DE LA JUSTICIA CONSTITUCIONAL}

Actualmente, la justicia constitucional “ortodoxa” está focalizada hacia las acciones propias del control constitucional a posteriori y se desarrolla frente a los órganos de naturaleza jurisdiccional identificados en la estructura del Poder Judicial Federal. ${ }^{9}$ Solamente el caso del juicio político se refiere a un procedimiento de naturaleza sui géneris que debe

${ }^{5}$ Esta afirmación que podría estar afectada de intolerancia debe leerse con cuidado: el Estado Constitucional es el único posible y defendible, pues es el Estado-tipo donde los derechos y las libertades son garantizados por la estructura estatal, la cual recibe de la Constitución sus atribuciones y sus límites. "En el Estado constitucional democrático, los ciudadanos y las personas, su dignidad humana, son la premisa "antropológica y cultural". Häberle, P., "El Estado constitucional europeo", en La constitucionalización de Europa, Carbonell, M. y Salazar, p. (Editores), UNAM, México, 2004. p. 24.

${ }^{6}$ Esta idea forma parte central de los trabajos de Diego Valadés. Véase particularmente su libro El control del poder, Instituto de Investigaciones Jurídicas, México, 1998.

${ }^{7}$ Miguel Covián Andrade prefiere denominarlos "sistemas" en lugar de modelos; es evidente que el término sistema resulta más completo, por ello remitimos al lector a la obra del citado autor El control de la constitucionalidad en el Derecho Comparado, Centro de Estudios de Ingeniería Política Constitucional, México, 2001, pp. 26 y 27, donde expone una interesante clasificación de estos sistemas.

${ }^{8}$ Remitimos al lector a nuestra obra Mecanismos para la Defensa de la Constitución en México, Universidad Autónoma del Estado de México, 2004.

${ }^{9}$ Excepción que podemos destacar en los países donde los Estados-miembros cuentan con un organismo especializado en esta materia y en los que es posible ensayar la jurisdiccional constitucional concurrente. 
desahogarse ante un órgano de naturaleza política; de cualquier forma, debe valorarse plenamente si, a partir de su ineficacia, este juicio debe seguir enquistado en el campo de la justicia constitucional; a nosotros nos parece que no, a menos que sea reestructurado al nivel de un auténtico juicio de responsabilidad constitucional. ${ }^{10}$

En la otra vertiente, con independencia de la forma de organización del Estado, la justicia constitucional es atendible desde la dimensión temporal que refleja las acciones de tipo preventivo (casi inexistentes en los ordenamientos latinoamericanos) ${ }^{11}$ y aquellas otras que se realizan después de que ha tenido lugar la violación constitucional, ya sea por la promulgación de normas jurídicas contrarias al texto de la norma normarum o por la realización de actos que vulneran el texto constitucional.

En Latinoamérica se ha puesto énfasis en los mecanismos de justicia constitucional de tipo correctivo; su tramitación tiene lugar ante las instancias jurisdiccionales definidas por el ámbito competencial de los órganos del Poder Judicial Federal. Cabe decir que ni aún con esa clara definición jurisdiccional, el control constitucional es capaz de operar de manera eficaz. Posiblemente la dificultad reside en el hecho de que ni siquiera todos esos instrumentos jurídicos encaminados a la realización del control constitucional tienen naturaleza eminentemente jurisdiccional, ${ }^{12}$ lo que se traduce en una serie inconexa de absurdos y conflictos de competencias que, a pesar de ser realizado por encargo del máximo Tribunal de cada país, resulta indiscutiblemente un procedimiento carente de pertinencia y eficacia.

Por ello, se hace necesaria la construcción de una posición doctrinal que supere la visión incompleta que hemos destacado. Esta perspectiva debe atender la importancia que tiene la temática de la defensa de la Constitución, para estar en posibilidades de armar un constructo teórico que nos permita afirmar que la justicia constitucional es una obligación de todos los órganos del Estado. Por eso, una mirada más amplia nos ha permitido advertir las peligrosas fisuras que muestra la justicia constitucional, más aún cuando el mismo órgano jurisdiccional ha asumido las dos grandes vertientes de la justicia aquí destacadas. ${ }^{13}$

La confusión doctrinal que se advierte entre normas jurídicas para la aplicación de la justicia ordinaria y normas para la aplicación de la justicia constitucional, es otra de las grandes debilidades en la aplicación de la justicia constitucional que hasta ahora

${ }^{10}$ Esta perspectiva ha sido analizada en la obra de nuestra autoría sobre El Tribunal Constitucional, Universidad Autónoma del Estado de México, 2002. Véase especialmente el capítulo cuarto relativo a la estructura y atribuciones propuestas para el funcionamiento de un verdadero Tribunal Constitucional.

${ }^{11}$ Chile es una excepción que podemos subrayar, pues en este país "El Tribunal Constitucional realiza dos clases de control: uno preventivo y otro a posteriori. El control preventivo lo ejerce sobre las leyes orgánicas constitucionales antes de su promulgación y de las leyes interpretativas de la Constitución..." Quinzio Figueiredo, J. M. Justicia constitucional en Chile, Centro de Estudios Constitucionales México Centroamérica, UNAM, Corte de Constitucionalidad República de Guatemala, México, 2000, p. 85.

12 Citemos el caso del llamado Procedimiento de investigación de la Suprema Corte de Justicia de la Nación que prevé la Constitución Mexicana en su artículo 97 o el recurso de apelación previsto en el artículo 303 de la Constitución Uruguaya.

13 "...la inclusión del Tribunal Constitucional dentro del Poder Judicial ba de ser considerada como muy desafortunada." Fernández, F., "La jurisdicción constitucional en la reforma de la Constitución de Bolivia de 1994”, en Una mirada a los Tribunales Constitucionales, las experiencias recientes, Comisión Andina de Juristas - Konrad Adenauer, Perú, 1995, p. 87. 
está limitada al control de la constitucionalidad. Si bien es cierto que en el escenario de la teoría del derecho la jerarquía del órgano no necesariamente define la jerarquía del ordenamiento jurídico aplicable, no hay que soslayar que por la alteza de los principios que salvaguarda, la justicia constitucional debe concebirse como un espacio reservado para la aplicación de los corpus de contenido esencial y para la actuación de los órganos especializados ${ }^{14}$ en la defensa de los "contenidos" de la Constitución y en el mantenimiento del orden jurídico nacido de la Constitución. ${ }^{15}$

\section{Prospectiva Deonto-Teleológica de la justicia constitucional}

¿Cómo construir un sistema de justicia constitucional eficaz en un estado federal? Tal es la cuestión. Según nuestro criterio, la justicia constitucional hasta aquí delineada necesita dos escenarios para su realización:

- El primero definido por los mecanismos ad hoc enmarcados en el diseño constitucional que ha propiciado un estado compuesto de tipo federal; en este sentido, los Estados-miembros (también identificados como entidades federativas) deben participar en la justicia constitucional.

- Otro basado en los instrumentos jurídicos -y de preferencia jurisdiccionales- aplicables y eficaces para la defensa de la Constitución y el control de la constitucionalidad que hemos identificado como los ámbitos estático y dinámico de la justicia constitucional.

En cuanto al primer escenario, baste con decir que es necesario contar con un sistema de control constitucional dual que dote de competencias en esta materia a los Estadosmiembros; existirá así la posibilidad de que en cada uno de éstos pueda constituirse un Tribunal Constitucional -competente para dirimir controversias y resolver cuestiones directamente conectadas con la vigencia y respeto de la Constitución local-. Es importante que las acciones de tipo preventivo inicien desde las entidades federativas con el respeto irrestricto al texto de la Constitución local. Además, es aconsejable que el propio órgano de control constitucional local pueda realizar -en vía de jurisdicción dual o concurrente- funciones de precontrol constitucional legislativo así como de control a posteriori, con respecto a preceptos de la Constitución federal.

\footnotetext{
${ }^{14}$ Aragón, M., "Principios Constitucionales”, en Temas básicos de Derecho Constitucional, Tomo I, Civitas, Madrid, 2001, p. 40

15 "La justicia constitucional asume generalmente, cualquiera que sea su organización, cuatro grandes tipos de misión: en primer término, el control de la regularidad de las elecciones y de las votaciones políticas, es decir, tanto de las elecciones legislativas y presidenciales, como de los referéndum; el respeto del equilibrio entre el Estado y las colectividades que aquél comprende, misión especialmente importante en un Estado Federal o cuasifederal, pero que -incluso en un Estado unitario como Francia- no está vacía de significado; por otra parte, la garantía del buen funcionamiento de los poderes públicos y de la distribución de poderes entre ellos; y por último, el control de constitucionalidad de las leyes y la protección de los derechos fundamentales." Favoreu, L., "Informe general introductorio", en Tribunales constitucionales europeos y derechos fundamentales. Favoreu, L., et al., Centro de Estudios Constitucionales, Madrid, 1984, pp. 22 y 23.
} 
Este diseño es congruente con la naturaleza del estado federal, donde la justicia constitucional verdaderamente tangible y eficaz debe armarse desde la composición de los Estados-miembros; por eso, nos permitimos señalar que la competencia dual del órgano de control constitucional de las entidades federativas, puede y debe ser extendida hacia el control de la constitucionalidad desde los espacios propios de los estados miembros, a fin de no permitir que los órganos locales incurran en violaciones a los principios contenidos en la Carta Magna.

En cuanto al segundo escenario, nos parece que aquí se halla la cuestión de mayor relieve, pues para poder señalar cuáles deben ser los instrumentos jurídicos viables para la justicia constitucional, tenemos que basarnos en el siguiente ejercicio metodológico.

\section{Elementos METODOLÓGICOS DEL SISTEMA}

Una vez que hemos dicho ya lo necesario en cuanto al aspecto estructural-orgánico ${ }^{16}$ de la justicia constitucional, en esta parte vamos a realizar el ejercicio tendente a señalar cuáles son los elementos metodológicos útiles para el establecimiento de mejores instrumentos que den viabilidad y eficacia al sistema de justicia constitucional en el estado federal.

Para ello debemos tomar en cuenta varios elementos:

Primero.- El escenario de su aplicación. Ya sea que se intente una acción de tipo preventivo o que se trate de ejercer una de tipo reparador.

Segundo. - La materia de su ejercicio. Bien sea que se trate de mantener el orden jerárquico-competencial interorgánico; que se procure la defensa de los derechos fundamentales de los habitantes; o que se defienda el núcleo constitucional. En este caso, podemos señalar tres grandes materias:

a. La defensa de atribuciones de los órganos.

b. La defensa de los derechos fundamentales.

c. La defensa del núcleo constitucional.

Tercero.- El objeto de su aplicación.

En este caso, es necesario identificar si la justicia constitucional se ejercerá para combatir actos o leyes contrarios a la Carta Magna.

Cuarto.- Los sujetos legitimados para intentar la acción correspondiente.

Quinto.- Instrumentos recomendables.

Sexto. - Los efectos de la resolución.

${ }^{16}$ Además de lo que aquí hemos señalado, remitimos al lector a nuestro texto Mecanismos... Op. cit., especialmente a la parte final que trata sobre las modalidades de la jurisdicción que a nuestro juicio acusan mayor pertinencia para hacer posible la justicia constitucional. 
En el siguiente cuadro podemos ver este diseño teórico.

\begin{tabular}{|c|c|c|c|c|c|}
\hline Escenario & Materia & Objeto & $\begin{array}{c}\text { Sujeto } \\
\text { legitimado }\end{array}$ & Instrumento & $\begin{array}{l}\text { Efectos } \\
\text { resolución }\end{array}$ \\
\hline A priori & $\begin{array}{l}\text { Competencias } \\
\text { interorgánicas }\end{array}$ & $\begin{array}{l}\text { Leyes, tratados y } \\
\text { reformas consti- } \\
\text { tucionales }\end{array}$ & $\begin{array}{l}\text { Órgano afectado por } \\
\text { la norma en proceso } \\
\text { de creación }\end{array}$ & $\begin{array}{l}\text { Acción previa de constitu- } \\
\text { cionalidad de leyes }\end{array}$ & $\begin{array}{l}\text { Declaración de inconsti- } \\
\text { tucionalidad, con efectos } \\
\text { de nulidad }\end{array}$ \\
\hline A posteriori & $\begin{array}{l}\text { Competencias } \\
\text { interorgánicas }\end{array}$ & $\begin{array}{l}\text { Leyes, tratados y } \\
\text { reformas consti- } \\
\text { tucionales }\end{array}$ & $\begin{array}{l}\text { Órgano afectado por } \\
\text { la norma creada }\end{array}$ & $\begin{array}{l}\text { Acción de inconstitucio- } \\
\text { nalidad de leyes }\end{array}$ & $\begin{array}{l}\text { Declaración de inconsti- } \\
\text { tucionalidad, con efectos } \\
\text { de nulidad erga omnes }\end{array}$ \\
\hline A posteriori & $\begin{array}{l}\text { Competencias } \\
\text { interorgánicas }\end{array}$ & Actos & $\begin{array}{l}\text { Órgano que ha su- } \\
\text { frido la invasión de } \\
\text { su competencia }\end{array}$ & $\begin{array}{l}\text { Controversia Constitu- } \\
\text { cional }\end{array}$ & $\begin{array}{l}\text { Declaración de inconsti- } \\
\text { tucionalidad, con efectos } \\
\text { generales de nulidad }\end{array}$ \\
\hline A priori & $\begin{array}{l}\text { Derechos fun- } \\
\text { damentales }\end{array}$ & $\begin{array}{l}\text { Leyes, tratados y } \\
\text { reformas consti- } \\
\text { tucionales }\end{array}$ & $\begin{array}{l}\text { Ciudadanos, Defen- } \\
\text { soría de Habitantes } \\
\text { Procuradurías de } \\
\text { Justicia }\end{array}$ & $\begin{array}{l}\text { Acción previa de constitu- } \\
\text { cionalidad de leyes }\end{array}$ & $\begin{array}{l}\text { Declaración de inconsti- } \\
\text { tucionalidad, con efectos } \\
\text { de nulidad }\end{array}$ \\
\hline A posteriori & $\begin{array}{l}\text { Derechos fun- } \\
\text { damentales }\end{array}$ & $\begin{array}{l}\text { Leyes, tratados y } \\
\text { reformas consti- } \\
\text { tucionales }\end{array}$ & $\begin{array}{l}\text { Ciudadanos, Defen- } \\
\text { soría de Habitantes } \\
\text { Procuradurías de } \\
\text { Justicia }\end{array}$ & $\begin{array}{l}\text { Acción de inconstitucio- } \\
\text { nalidad de leyes }\end{array}$ & $\begin{array}{l}\text { Declaración de inconsti- } \\
\text { tucionalidad, con efectos } \\
\text { de nulidad erga omnes }\end{array}$ \\
\hline A posteriori & $\begin{array}{l}\text { Derechos fun- } \\
\text { damentales }\end{array}$ & Actos & $\begin{array}{l}\text { Ciudadanos, Defen- } \\
\text { soría de Habitantes } \\
\text { Procuradurías de } \\
\text { Justicia }\end{array}$ & $\begin{array}{l}\text { - Acción de inconstitu- } \\
\text { cionalidad } \\
\text { - Juicio para la protección } \\
\text { constitucional de los } \\
\text { derechos humanos } \\
\text { - Acción popular } \\
\text { - Acción de clase } \\
\text { - Acción de grupo } \\
\text { - Juicio de responsabili- } \\
\text { dad constitucional }\end{array}$ & $\begin{array}{l}\text { Declaración de inconsti- } \\
\text { tucionalidad, con efectos } \\
\text { de nulidad erga omnes. } \\
\text { Además de los efectos } \\
\text { generales, imposición } \\
\text { de sanciones penales, } \\
\text { administrativas y políti- } \\
\text { cas-constitucionales }\end{array}$ \\
\hline A priori & $\begin{array}{l}\text { Núcleo consti- } \\
\text { tucional }\end{array}$ & $\begin{array}{l}\text { Leyes, tratados y } \\
\text { reformas consti- } \\
\text { tucionales }\end{array}$ & $\begin{array}{l}\text { Ciudadanos, Defen- } \\
\text { soría de Habitantes } \\
\text { Procuradurías de } \\
\text { Justicia }\end{array}$ & $\begin{array}{l}\text { Acción previa } \\
\text { de constitucio- } \\
\text { nalidad de leyes }\end{array}$ & $\begin{array}{l}\text { Declaración de inconsti- } \\
\text { tucionalidad, con efectos } \\
\text { de nulidad }\end{array}$ \\
\hline A posteriori & $\begin{array}{l}\text { Núcleo consti- } \\
\text { tucional }\end{array}$ & $\begin{array}{l}\text { Leyes, tratados y } \\
\text { reformas consti- } \\
\text { tucionales }\end{array}$ & $\begin{array}{l}\text { Ciudadanos, Defen- } \\
\text { soría de Habitantes } \\
\text { Procuradurías de } \\
\text { Justicia }\end{array}$ & $\begin{array}{l}\text { Acción de inconstitucio- } \\
\text { nalidad de leyes }\end{array}$ & $\begin{array}{l}\text { Declaración de inconsti- } \\
\text { tucionalidad, con efectos } \\
\text { de nulidad erga omnes }\end{array}$ \\
\hline A posteriori & $\begin{array}{l}\text { Núcleo consti- } \\
\text { tucional }\end{array}$ & Actos & $\begin{array}{l}\text { Ciudadanos, Defen- } \\
\text { soría de Habitantes } \\
\text { Procuradurías de } \\
\text { Justicia }\end{array}$ & $\begin{array}{l}\text { - Acción de inconstitu- } \\
\text { cionalidad } \\
\text { - Juicio para la protección } \\
\text { constitucional de los } \\
\text { derechos humanos } \\
\text { - Habeas Data } \\
\text { - Acción popular } \\
\text { - Acción de clase } \\
\text { - Acción de grupo } \\
\text { - Juicio de responsabili- } \\
\text { dad constitucional } \\
\text { - Revocación de mandato }\end{array}$ & $\begin{array}{l}\text { Declaración de incons- } \\
\text { titucionalidad, con } \\
\text { efectos de nulidad erga } \\
\text { omnes. } \\
\text { Además de los efectos } \\
\text { generales, imposición } \\
\text { de sanciones penales, } \\
\text { administrativas y políti- } \\
\text { cas-constitucionales }\end{array}$ \\
\hline
\end{tabular}


En este esquema advertimos la forma en que los estados federales pueden construir un genuino sistema de justicia constitucional que permita la participación de los Estadosmiembros en dicha tarea. En la explicación que a continuación anotamos, se aprecia la dinámica de su composición y la manera como puede funcionar dicho sistema.

En primer término, debe quedar claro que la justicia constitucional es algo absolutamente distinto de la justicia ordinaria. Como ya fue señalado, la justicia constitucional comprende los mecanismos e instrumentos que están enfocados hacia el control de la constitucionalidad y la defensa de la Constitución. De esta forma, la defensa de la Constitución se traduce en el mantenimiento de los principios y valores que ella sanciona. Para la mejor comprensión de esta importante cuestión de la justicia constitucional, podemos apoyarnos en nuestra tesis sobre el núcleo constitucional, según la cual, más allá de los artículos sobre derechos fundamentales y de las disposiciones sobre la organización del Estado, existen otros preceptos que no caben en ninguno de los dos ámbitos antes referidos y que constituyen el corazón mismo de la Constitución. Se trata de la zona de mayor relieve en el diseño de la Carta Magna; es el andamiaje mismo de la Constitución que no reconoce otro titular que el pueblo.

Esa parte central de la Constitución es la que necesita ser defendida desde cualquier momento e incluso a través del acatamiento de la norma; ${ }^{17}$ es más, al margen de que existan o no violaciones a la lex fundamentalis. Con esto no queremos decir otra cosa que la defensa de la Constitución es la más elemental, primaria e inmediata de las acciones que gobernantes y gobernados pueden y deben realizar para el mantenimiento del sustratum de esa ley fundamental. La defensa de la Constitución se distingue del control de la constitucionalidad básicamente por la forma en que ambos conceptos se actualizan. El control de la constitucionalidad -expresión dinámica de la justicia constitucional- tiene lugar y es procedente para la defensa de los derechos fundamentales de los habitantes y para el mantenimiento de los ámbitos competenciales entre órganos, normalmente por la vía jurisdiccional. La defensa de la Constitución -aspecto estático de la justicia constitucional- no necesita actualizarse en los tribunales, aunque el contenido de la actividad que se desarrolla a través del control de la constitucionalidad, sin duda forma parte de ella.

Pues bien, en el esquema antes referido podemos ver que un sistema de justicia constitucional necesita al menos los seis rubros aquí señalados. En cuanto al escenario que comparten tanto la defensa de la Constitución como el control de la constitucionalidad, creemos que no hay más que dos momentos para su realización: La fase preventiva y la de corrección.

La primera que aquí hemos llamado escenario a priori, está constituida por las acciones que es posible intentar antes de que se consume la violación a la Carta Magna en cualquiera de sus vertientes. El segundo escenario, denominado a posteriori, se actualiza cuando ya la violación al orden constitucional ha sido consumada; en tal caso, las variantes para hacer

${ }^{17}$ Para que se comprenda mejor esto, debemos decir que la defensa de la Constitución, identificada con la estática constitucional tiene lugar incluso fuera de litis, y tal vez sea esta su mejor expresión, pues desde el momento en que los gobernados cumplen con la ley y los gobernantes ciñen su conducta a los ordenamientos que regulan su desempeño, la defensa de la Constitución cobra vida y actualidad. 
frente a tal situación dependen del tipo de violación cometida, ya sea que se trate de una norma de carácter general o que se haya atentado contra los derechos de los habitantes o que el núcleo constitucional haya sido trastocado.

En el segundo rubro nos referimos a la materia en que dichos escenarios pueden cobrar vigencia. Tenemos en este caso las competencias entre órganos, los derechos fundamentales y el núcleo constitucional. Luego de un ejercicio de interpretación y de repetidos ensayos, nos parece que son estas tres materias las que conforman la justicia constitucional: Las competencias entre órganos como la tarea esencial e insoslayable para mantener el equilibrio de poderes, tanto en su expresión horizontal como vertical; id. est. que en el diseño de un Estado que se estructuró a partir del modelo federal, el ejercicio de la potestad tiene que conducirse necesariamente con base en el respeto invariable a los dos ${ }^{18}$ ámbitos competenciales reconocidos por la Constitución. En este contexto, cada nivel de gobierno, cada órgano federal o estatal, tiene que colmar su propio espacio -constitucional y legalmente reconocido- para que tenga lugar su actuación legítima; es evidente que en este escenario no opera el tan citado principio de que "el que puede lo más puede lo menos"; aquí, hablando de competencias interorgánicas, cada órgano -así sea el de más alta jerarquía- sólo puede y debe hacer lo que la ley le señala. No más, pero tampoco menos.

También siguiendo este mismo criterio, en el caso de las relaciones interorgánicas en sentido horizontal, es palmario que cada órgano de la clásica "división de poderes" debe ceñir sus actos a lo prescrito por los ordenamientos que regulan su actuación. Aquí no cabe ningún argumento para que tal delimitación competencial pueda ser desatendida; incluso en el caso de alguno de los “poderes”, los órganos que a él pertenecen también tienen definida su competencia; por este principio, no podemos admitir que órgano alguno de la dimensión conceptual que se quiera, pueda desbordar su espacio natural de actuación que son, sin más, las normas que lo han creado y las que lo han dotado de competencia.

De acuerdo con lo que hemos señalado, los conflictos de competencia pueden tener lugar incluso al interior de un mismo órgano del Estado, por lo cual es importante deslindar lo que son los típicos conflictos competenciales interorgánicos de los conflictos de atribuciones intraorgánicos; estos últimos nada tienen que ver con la materia que nos ocupa, pues para ser esclarecidos y resueltos, normalmente la vía administrativa resulta ser el camino correcto. Pensemos, a manera de ejemplo, en un conflicto entre secretarías del gobierno de alguna entidad federativa como puede tener lugar cuando el área competente en materia de seguridad pública pone en marcha algún operativo para prevenir la comisión de delitos; si esta acción implica la toma de decisiones con incidencia en el ámbito de alguna otra secretaría, es claro que estamos frente a un conflicto de atribuciones intraorgánico, habida cuenta de que sus actores son dos secretarías de un mismo "poder" -el ejecutivo en este caso-; en tal supuesto, el conflicto de atribuciones encuentra en las normas ordinarias su salida normal. Distinto es el escenario que se plantea cuando alguna de las partes en conflicto alega a su favor la

${ }^{18}$ Es oportuno comentar que algunos autores sostienen la existencia de tres niveles de gobierno; desde este punto de vista, los Municipios constituyen el otro espacio competencial que se suma a los ámbitos federal y estatal. 
violación de alguna norma constitucional, pues en tal supuesto y sólo en él, este conflicto inicialmente de atribuciones se convierte en un conflicto de competencias.

Pasando a otra perspectiva de la misma materia en comento, nos vamos a referir al caso de la violación a derechos fundamentales que encierra indiscutible relevancia para la justicia constitucional; y es que al margen de la estructura del Estado que ha sido diseñada en diversos ámbitos competenciales, la defensa de los derechos de los habitantes es, sin duda, el otro continente de suma importancia para la justicia constitucional. En lo tocante a esta cuestión, consideramos que la parte más difícil no se encuentra en la definición o en el concepto que de algún autor podamos tomar como el más adecuado, sino en la concepción que seamos capaces de construir desde una visión integral ${ }^{19}$ en la que estén comprendidos los mecanismos e instrumentos para garantizar la eficacia de su defensa. El ser jurídicamente exigibles es lo que representa la parte más interesante de esta concepción, pues en nuestro criterio de nada sirven las mejores construcciones conceptuales si en la parte pragmática nos enfrentamos a lo irrealizable o, peor aún, ante lo indefendible. Tratándose de los derechos de los habitantes, el mayor reto de las sociedades contemporáneas ni duda cabe, es su defensa eficaz.

Con esta referencia, la materia que constituyen los derechos fundamentales es otro segmento del control de la constitucionalidad que debe ser analizado y dotado de las más adecuadas herramientas para su defensa jurídica, posible, viable, eficaz. De igual manera que en el caso de las competencias interorgánicas, también los derechos fundamentales pueden ser violentados en los grandes escenarios ya explicados. Por supuesto, las garantías tienen que servir para la prevención de las violaciones y en su defecto para remediar sus consecuencias. $^{20}$

Aunque la violación-tipo en este caso tiene lugar de manera superlativa en el escenario $a$ posteriori, merced a que los actos atentatorios de estos derechos no pueden ser sino conductas ya consumadas, no podemos desconocer que a priori puede tener lugar la violación a derechos fundamentales por la vía de la aprobación de leyes que por su "contenido" impliquen claros atentados contra los derechos de los habitantes. De cualquier forma, el Estado tiene que poner al alcance de los habitantes los instrumentos jurídicos que permitan el ejercicio del elemental derecho a defender lo más preciado del ser humano.

Siguiendo el orden de nuestro análisis, es necesario hacer referencia a lo que hemos denominado el núcleo constitucional. Es conveniente decir que la moderna teoría constitucional apenas empieza a otear esta perspectiva; si bien, todo parece indicar que un sistema de justicia constitucional puede construirse con base en el diseño de mecanismos e instrumentos para el mantenimiento de los ámbitos competenciales y para la defensa de los derechos humanos, no podemos negar la existencia de una tercera materia que no se refiere ni a estructura del Estado ni a derechos de los habitantes, sino a las declaraciones esenciales que atribuyen una

19 A partir de esta idea, podemos señalar que los derechos humanos son los atributos que corresponden a la naturaleza de ser humano, oponibles frente a cualquier persona, indispensables para la autorrealización y jurídicamente exigibles.

${ }^{20}$ Guastini, R., Estudios de teoría constitucional, Fontamara, México, 2001, p. 234. 
fisonomía propia al pueblo y al Estado. Desde una óptica general, el núcleo constitucional incluye estos dos espacios, aunque desde luego es más amplio.

Un ejemplo basta para explicar esta cuestión: En general las constituciones latinoamericanas señalan que la soberanía es un atributo del pueblo. ${ }^{21}$ Si algún intento de reforma constitucional propusiera cambiar el sentido de esta expresión, queda claro que no se podría configurar ni una violación a derechos humanos ni un conflicto de competencias interorgánicas; por eso, en nuestra propuesta señalamos que el núcleo constitucional es la parte dura, la zona central de la Constitución que sin mayor discusión podemos identificar en los principios constitucionales. ${ }^{22}$

Como se ve, es evidente la pertinencia de que la Constitución contenga una declaración expresa acerca de los artículos que recogen prescripciones de primer orden y que conforman el referido núcleo. En este orden de ideas, se ha dicho que los valores son exclusivamente fines y los principios, en cambio, prescripciones jurídicas generalísimas ${ }^{23}$; pero hay quien afirma que los valores superiores son las normas portadoras de contenidos o pronunciamientos valorativos o axiológicos más universales del ordenamiento del Estado ${ }^{24}$. Nos parece que la diferencia entre valores y principios es sólo de grado, pues los valores se manifiestan en aspiraciones más amplias y más generales y los principios en proyecciones más condensadas. Con todo, los valores y los principios necesitan una redacción explícita en la ley, pues la "concreción legislativa" 25 es lo que permite su aplicación en la realidad. Con lo hasta aquí llevamos recorrido, podemos decir que estas tres materias encierran la totalidad de posibilidades para la justicia constitucional. Hasta este momento, fuera de este contexto, no hay otras expresiones que pudieran dar lugar a una materia distinta.

Pasando a otro punto, tenemos que referirnos al objeto de atención de la justicia constitucional. Los objetos en cualquiera de los escenarios y materias son dos: Las leyes y los actos. No hay más que estos dos agentes para llevar a cabo un acto contrario a lo contenido en la Constitución. Las leyes y disposiciones normativas con tal carácter -entre las que incluimos a los tratados internacionales y las reformas a la Constitución- son la vía común para trastocar las competencias entre órganos, así como para vulnerar los derechos fundamentales y para conculcar las declaraciones esenciales del núcleo constitucional.

Podrá alegarse que los tratados no son leyes o que las reformas constitucionales tienen una dimensión jurídica superior; sin entrar al fondo de esta discusión, nos parece suficiente

${ }^{21}$ Art. 33 de la Constitución Argentina; artículo 2 de la Constitución de Bolivia; artículo 5 de la Constitución de Chile; artículo 1 de la Constitución de Ecuador; artículo 39 de la Constitución Mexicana; artículo 3 de la Constitución de Perú.

${ }^{22}$ Los principios constitucionales incluyen a las “decisiones políticas fundamentales" (expresión acuñada por el constitucionalista Jorge Carpizo) que preferimos denominar cláusulas pétreas tácitas, toda vez que no tienen una redacción expresa que permita su identificación inequívoca.

23 Aragón, op. cit. p. 42.

${ }^{24}$ Parejo, L., "Constitución y valores del ordenamiento", en Estudios sobre la Constitución Española, Homenaje al profesor Eduardo García de Enterría, Tomo I, Civitas, Madrid, 1991, p. 131.

25 Tomás y Valiente, F., Escritos sobre y desde el Tribunal Constitucional, Centro de Estudios Constitucionales, Madrid, 1993, p. 166. 
con decir que hemos incluido a tratados y reformas constitucionales ${ }^{26}$ en este catálogo, porque inevitablemente unos y otras tienen una expresión normativo-jurídica y su generación inconstitucional debe encontrar límites y mecanismos para garantizar el respeto y vigencia de la lex fundamentalis.

En lo tocante a los actos, estos sin duda ocupan la mayor parte de casos en que surge alguna cuestión que se estima inconstitucional. También es evidente que, por su naturaleza, estos "objetos" de la justicia constitucional solamente tienen lugar en el escenario a posteriori, una vez que se han consumado las conductas que acarrean la problemática que nos ocupa. Aquí está uno de los grandes problemas de la justicia constitucional. ¿Cómo combatir los actos que conculcan el orden constitucional? Hay todavía una parte más árida en este campo, ¿cómo llevar a cabo la vuelta a la "normalidad constitucional"? y, ¿a través de qué mecanismos e instrumentos es posible realizar la reparación constitucional? Este es el punto más álgido de la cuestión; aquí reside la médula del problema sobre el control de la constitucionalidad; esta problemática no es tan escabrosa tratándose de leyes (ni siquiera en el supuesto de la reforma constitucional) habida cuenta de que las normas jurídicas pueden ser declaradas nulas con efectos erga omnes y ahí el asunto queda concluido. Tratándose de actos, la operación es más complicada y el grado de complejidad se incrementa si la materia son los derechos fundamentales o el núcleo constitucional. En el caso de los primeros, se corre el riesgo de que las acciones de reparación no sirvan para enderezar la inconstitucionalidad cometida; en el caso de lo segundo, existe la posibilidad de que las conductas lesivas ni siquiera puedan ser sancionadas.

Es por ello que al mirar hacia las posibilidades reales para combatir y remediar lo que llamaríamos la injusticia constitucional, tenemos que ser enfáticos en los tres rubros restantes. El primero se refiere a los sujetos legitimados; aquí no puede haber mucha diferencia de opiniones, pues el sujeto legitimado tiene que ser, en primer término, aquél que directamente ha sufrido el agravio o la injusticia constitucional, con excepción de los casos relativos a la defensa de los derechos supraindividuales o intereses plurisubjetivos, ${ }^{27}$ en cuyo supuesto el agravio indirecto deberá ser causa suficiente para actualizar la legitimación procesal. Lo más interesante, nos parece, es que no se agota aquí la posibilidad de poner en movimiento el aparato estatal para la defensa de la Constitución, pues en los dos supuestos que identificamos como violaciones a derechos humanos y actos enderezados contra el núcleo constitucional, la legitimación incluso puede recaer en cualquier ciudadano, en las Defensorías de Habitantes y en las Procuradurías de Justicia.

Mucho falta todavía para poder empezar a usar este lenguaje con familiaridad; la legitimación estacionada en la idea de que "sólo aquél que sufre un agravio personal y directo” puede intentar la acción correspondiente, no resiste en la actualidad las exigencias

${ }^{26}$ Es posible que en este punto se retome la discusión sobre la posibilidad de que una reforma a la Constitución pueda ser inconstitucional. Dejamos de lado en este trabajo la referida cuestión -de alto grado de dificultad técnica por cierto-, siendo suficiente con señalar que según nuestro criterio sí es posible que las adecuaciones a la Carta Magna puedan ir en contra de algunos de sus más elevados preceptos.

${ }^{27}$ Bachmaier, L., "La tutela de los derechos e intereses colectivos de consumidores y usuarios en el proceso civil español", en Ovalle, J., (coord.), Las acciones para la tutela de los intereses colectivos o de grupo, UNAM, México, 2004, p. 20. 
de un modelo teórico en el que los derechos humanos de proyección colectiva tienen que ser defendidos -incluso más allá del Estado-. Esta misma exigencia se visualiza tratándose del núcleo constitucional, cuyos "contenidos" conculcados por los órganos del Estado no pueden ser defendidos pues aunque se agravie al conjunto de los habitantes lo extraño es que no exista "agravio personal y directo". Estas incongruencias, que muestran la fragilidad de algunos sistemas de justicia constitucional, nos permiten sostener la urgencia de su revisión y adecuación a los tiempos que vivimos.

En cuanto a los instrumentos y los efectos de las resoluciones, solamente queremos señalar que tratándose de violaciones al ordenamiento fundamental del Estado cuyos contenidos son esenciales, los efectos de las resoluciones tienen que servir para anular el acto o la ley que haya generado la violación. Es tiempo ya de incluir los efectos generales de las sentencias e incluso de las opiniones consultivas ${ }^{28}$, como parte de la justicia constitucional, pues sólo los efectos erga omnes pueden garantizar la eficacia de los instrumentos jurisdiccionales diseñados para anular los efectos de actos y leyes inconstitucionales.

\section{INSTRUMENTOS PARA LA JUSTICIA CONSTITUCIONAL}

No podríamos concluir este estudio sin enunciar, al menos, los instrumentos que nos parecen pertinentes para esta relevante función del Estado de Derecho:

1.- Acción previa de constitucionalidad, para evitar la aprobación de "leyes" contrarias a la Constitución.

2.- Acción de inconstitucionalidad, para intentar la reparación de las violaciones constitucionales, derivadas de la existencia de un agravio materializado en algún acto o en la aprobación de alguna ley.

3.- Controversia constitucional que en este estudio preferimos denominar en singular, pues en cada acción solamente podrá plantearse un conflicto interorgánico y, desde luego, una sola controversia; la controversia constitucional tendrá como escenario a posteriori los conflictos por competencias interorgánicas; la legitimación correrá a cargo del órgano que estime que su ámbito competencial haya sido vulnerado; los efectos de la resolución -como en la generalidad de los instrumentos para la justicia constitucional- serán la declaración de inconstitucionalidad y los efectos erga omnes.

${ }^{28}$ Los efectos generales de las opiniones consultivas solicitadas al órgano jurisdiccional especializado en justicia constitucional -principalmente por los órganos legislativos del Estado- se justifican por la jerarquía del ordenamiento jurídico susceptible de ser transgredido si la "ley" en ciernes no es sometida al control preventivo de la constitucionalidad. En este caso, proponemos que cuando el Congreso de la Unión, o alguna legislatura local, solicite en vía consultiva la opinión acerca de la constitucionalidad de algún proyecto legislativo o incluso de reforma constitucional, la "opinión” que recaiga sobre el caso planteado deberá tener efectos erga omnes como si cualquier otra instancia la hubiera solicitado. 
4.- Juicio para la protección constitucional de los derechos fundamentales, encaminado a la protección y defensa de los derechos fundamentales, pues la justificación de la existencia de todo el sistema de justicia constitucional está en el ser humano; de nada sirven ni el Estado ni sus instituciones si los derechos de los habitantes no están garantizados. Por ello, sostenemos la conveniencia de que, al margen de la importante actividad realizada por el sistema no jurisdiccional de protección de los derechos humanos, existan instrumentos de índole jurisdiccional para asegurar el respeto a ésta, la parte más importante de la Constitución.

Este juicio deberá intentarse por el agraviado en primer término, pero deberá existir la posibilidad de que las Comisiones Públicas de Derechos Humanos y las Procuradurías de Justicia, tengan legitimación para iniciar la demanda correspondiente. En el tema de los derechos de los habitantes, las cuestiones procesales deben ofrecer escenarios menos rígidos; por ello, consideramos que la legitimación no deberá ser tema de fondo, particularmente cuando se intente la defensa de derechos colectivos, pues en la actualidad algunas legislaciones incurren en el absurdo de que cuando por determinado acto se agravia a muchos, ninguno tiene legitimación para apersonarse en juicio.

Este juicio será procedente para la defensa de los derechos humanos individuales y colectivos, con independencia de lo que en el caso concreto pudieran resolver los Organismos Públicos Defensores de Derechos Humanos.

5.- Acción popular, para la realización de una doble función: En primer término, destaca la pertinencia de este instrumento para el control de la constitucionalidad en el caso-tipo de la violación a derechos fundamentales por actos; pero resulta todavía más atractivo si se le mira desde la posibilidad de que sirva para la defensa constitucional mediante el combate de los actos que vulneren el núcleo constitucional.

Este instrumento puede paliar incontables agravios que los habitantes padecen, pero que por ser "violaciones indirectas" poco se toman en cuenta y menos se atienden; dicha cuestión cobra mayor relieve si consideramos que la acción popular sirve para tutelar bienes jurídicos que carecen de otros instrumentos de protección. ${ }^{29}$

6.- Acción de clase, cuyo accionar será permitido a cualquier habitante siempre y cuando los derechos violentados sean compartidos por varias personas. Estamos ante el caso de los llamados derechos colectivos ${ }^{30}$ o difusos, cuya defensa en la actualidad es poco viable por no tener un titular claramente identificado.

${ }^{29}$ Vid. Esguerra, J. C., La protección constitucional del ciudadano, Legis, Bogotá, 2004, p. 217.

${ }^{30}$ Una definición que indica los alcances de los derechos colectivos señala que son el: "Conjunto de situaciones jurídicas, en principio descritas en el derecho objetivo, que son necesarias para el mantenimiento o procuración del bienestar político, histórico, social, ambiental, cultural o económico de la colectividad en un momento dado". Botero, L. F., Acción popular y nulidad de actos administrativos, protección de derechos colectivos, Legis, Colombia, 2004, p. 63. 
7.- Juicio de responsabilidad constitucional, que abrirá la posibilidad real de demandar a los servidores públicos y particularmente a los funcionarios del más alto nivel cuando transgredan el orden constitucional. En este sentido, nuestra preocupación gira en torno a la impunidad que lamentablemente impera de manera vergonzante en casi todos los ámbitos de la vida pública. A esto se suman la vaguedad de muchos ordenamientos legales que resultan de imposible aplicación ante la imprecisión de su telos y la confusión que impera en el tema de la responsabilidad constitucional que hasta ahora se ha embozado en el inoperante juicio político y en otros mecanismos de responsabilidad "administrativa".

Una de las fallas más visibles de los sistemas de responsabilidades es que idénticos supuestos son aplicables a cualquier servidor público, con lo cual se dejan de lado dos elementos esenciales para la determinación de las sanciones correspondientes y que son el nivel jerárquico y la intensidad del agravio cometido. No debemos pasar por alto que en la definición de estos dos elementos reside una parte importante de la eficacia de cualquier régimen de responsabilidades. Por ello y de acuerdo con las tres materias que se deben preservar en un verdadero sistema de justicia constitucional, la acción jurisdiccional que aquí se propone deberá reemplazar al juicio político para iniciar la construcción de un genuino instrumento de control constitucional de actos.

8.- Revocación de mandato, para dar viabilidad al incuestionable derecho que les asiste a los mandantes de retirar el encargo a cualquiera de sus mandatarios en el momento en que se considere que su actuación no se ajusta a las disposiciones normativo jurídicas que enmarcan sus atribuciones. Con todo ello, la revocación de mandato debe sujetarse a ciertos lineamientos necesarios para evitar que, al menor malestar de los habitantes, la elección democrática y hasta la designación de los servidores públicos, corra el riesgo de ser expuesta a los naturales vaivenes de la vida política.

Este instrumento deberá valorarse con toda acuciosidad, pues no podemos dejar de señalar el interesante debate que, tiene lugar cuando se habla de legitimidad y representación. A fin de cuentas, los derechos político electorales apenas empiezan a vislumbrarse en el horizonte de los derechos fundamentales; mientras estos que son de la primera generación no estén absolutamente garantizados, las disquisiciones sobre los otros derechos humanos de segunda y tercera generación, seguirán siendo referente obligado de estos temas, pero igualmente dejarán esa sensación de vacío e impotencia que se percibe ante lo indefendible.

\section{CONClusiones}

Primera. - La justicia constitucional entraña el más completo sistema para la defensa de la Constitución y el control de la constitucionalidad de actos y de leyes.

Segunda.- En los Estados federales la justicia constitucional debe realizarse mediante mecanismos de jurisdicción dual que permitan la participación de las entidades federativas e instrumentos jurídicos que permitan el precontrol constitucional legislativo y el control constitucional orgánico. 
Tercera.- Un ejercicio prospectivo nos permite señalar la conveniencia de que el sistema de justicia constitucional en los Estados federales tome en consideración seis aspectos básicos: El escenario de su aplicación; la materia sobre la que versará el procedimiento; el objeto de su aplicación; los sujetos legitimados; los instrumentos y los efectos de la resolución.

Cuarta.- De acuerdo con esto, algunos instrumentos aplicables en el Estado federal en materia de justicia constitucional pueden ser: La acción previa de constitucionalidad, la acción de inconstitucionalidad, la controversia constitucional, la acción popular, las acciones colectivas, el juicio para la protección de los derechos humanos, el juicio de responsabilidad constitucional, la revocación de mandato, entre otros.

\section{BIBLIOGRAFÍA}

Aragón Reyes, Manuel, "Principios Constitucionales", en Temas básicos de Derecho Constitucional Tomo I. Civitas. Madrid, 2001.

Bachmaier Winter, Lorena, "La tutela de los derechos e intereses colectivos de consumidores y usuarios en el proceso civil español”, en Las acciones para la tutela de los intereses colectivos o de grupo. Ovalle Favela, José (Coordinador) UNAM. México, 2004.

Botero Aristizábal, Luis Felipe, Acción popular y nulidad de actos administrativos. Protección de Derechos Colectivos. Legis. Bogotá, 2004.

Cappelletti, Mauro, "Necesidad y legitimidad de la justicia constitucional", en Tribunales constitucionales europeos y derechos fundamentales. Centro de Estudios Constitucionales. Madrid, 1984.

Covián Andrade, Miguel, El control de la constitucionalidad en el Derecho Comparado. Centro de Estudios de Ingeniería Política Constitucional. México, 2001.

Esguerra Portocarrero, Juan Carlos, La protección constitucional del ciudadano. Legis. Bogotá, 2004.

FAVOREu, Luis. "Informe general introductorio", en Tribunales constitucionales europeos y derechos fundamentales. Favoreu, Luis, et al. Centro de Estudios Constitucionales. Madrid, 1984.

Fernández Segado, Francisco, "La jurisdicción constitucional en la reforma de la Constitución de Bolivia de 1994", en Una mirada a los Tribunales Constitucionales, las experiencias recientes. Comisión Andina de Juristas - Konrad Adenauer. Lima, 1995.

Häberle, Peter, "El Estado constitucional europeo", en La constitucionalización de Europa, Carbonell, Miguel y Salazar, Pedro (Editores)., UNAM, México, 2004.

Guastini, Riccardo, Estudios de teoría constitucional. Fontamara. México, 2001.

Parejo Alfonso, LuCiano, "Constitución y valores del ordenamiento", en Estudios sobre la Constitución Española, Homenaje al profesor Eduardo García de Enterría, Tomo I. Civitas, Madrid, 1991.

Quinzio Figueiredo, Jorge Mario, Justicia constitucional en Chile, Centro de Estudios Constitucionales México Centroamérica, UNAM, Corte de Constitucionalidad República de Guatemala, México, 2000, p. 85.

Tomás y Valiente, Francisco, Escritos sobre y desde el Tribunal Constitucional. Centro de Estudios Constitucionales. Madrid, 1993.

Uribe Arzate, Enrique, El Tribunal Constitucional. UAEM. México, 2002.

- Mecanismos para la defensa de la Constitución en México. UAEM. México, 2004.

VAladés, Diego, El control del poder. Instituto de Investigaciones Jurídicas. México, 2000. 